\title{
Research on the present situation of physical education in primary schools of Zhumadian city
}

\author{
Ya-Hui WANG ${ }^{1,2}$, Qun Xiong ${ }^{1,2}$, Fei Chen ${ }^{1,2}$ and Jiang-Hua $\mathrm{Li}^{1,2, a}$ \\ ${ }^{1}$ Training monitoring and intervention laboratory of the sports in water, Key Laboratory of the State \\ Sports General Administration, Nanchang, 330022, China; \\ ${ }^{2}$ Institute of Physical Education, Jiangxi Normal University, Nanchang, 330022, China. \\ alijianghua8@sina.com
}

Keywords: physical education, primary school, sport teaching.

\begin{abstract}
To fully understand the present situation of physical education in primary schools of Zhumadian city, this paper presented a survey on the degree of attention on physical education and the teaching levels of the teachers in primary schools. The results show the sports facilities and equipment, professional and experienced physical education teachers, are short, the evaluation system for the physical education teachers is not reasonable, and most of the schools surveyed do not pay enough attention to the physical education for primary students.
\end{abstract}

\section{Introduction}

Physical education (PE) is one of the important parts of school education in our country. It is to carry out education policy, one aspect of school education in the purpose of the task. PE teaching is also an important content of Primary education [1].

China is a large country with a billion-plus population, occupies very important position in the world. The current, compared with developed countries, our country's national sports still have a considerable distance. In Das Capital, the leader of the revolution Marx points out that the future education for all children has reached a certain age, is combining intelligence and sports in productive labor, and it is not only one way to improve the social production, but it is the only way to make the person all-round development of people. The great leader Chairman Mao in the A study of physical culture, the significance, function and method of sports the incisive, He said: "sports together with the moral education and intellectual education, and wisdom are sent in body, no body is any moral education." Teenagers are the future of our motherland, is the construction of the talents in the 21st century, if you don't have very strong body, the social responsibilities can't be taken on. So physical exercise is conducted on students, but primary school sports education is a weak link. That is to say, the issue of PE teaching in primary school is a matter of problem.

It is well known of "the sunshine project" in primary schools in China: "Exercise an hour every day, health work for fifty years, a happy life for a lifetime” [2]. Using a variety of methods to Zhumadian primary schools PE present situation investigation, analysis and research. It is found that the teaching content is tedious, boring. It doesn't meet the standards the national sport general administration stipulates. Meanwhile it also can’t meet the needs of pupils in improving physical quality to promote the development in mental and physical. And the principles of evaluation in teaching assessment and summative assessment, even including teaching attitude in the PE teachers, but if scientific teaching methods have not been applied in teaching, the atmosphere of classroom is depressing, and it is not conducive to the primary school PE and healthy development of sports teaching [3-5]. This is worth for us pondering and exploring the important subject. 


\section{Method}

Subjects. The PE teachers of the thirty primary schools in Zhumadian city, including Cedar Road Primary School, Long Feng primary school, Experimental Primary School, Yu Ying primary school, Ze Ying primary school, Bilingual Primary School, etc..

Questionnaire. The random sampling method to determine the object of investigation, and questionnaire to understand the Zhumadian city primary school PE status of the investigation object, on the questionnaire designed for filtering content and supplemented by experts. Questionnaires were distributed into 150 copies of the questionnaire. The content experts were screened and supplementary questionnaire consisting with questionnaires design, following the principle of design. Totally, 139 questionnaires were taken back. The recovery rate is $92.7 \%$ and effective questionnaire 122, effective rate was $87.8 \%$.

\section{Results and Discussion}

In order to have a comprehensive understanding of primary school PE teachers, we try to compare them in this city. To strengthen sports teaching work, we will made questionnaires about intention. From February 2013 starting from zhumadian primary school it has been carried on the issue, adopting the way of making direct answer. It is the combination of questionnaire and individual conversation as well as online information query; the specific analysis is as follows:

School sport site and facilities and sport equipment. As table 1 shows, the evaluation is classified as very good, general, poor and very poor, and the most subjects' evaluation is poor on both the schools' sport sites and facilities and the schools' sport equipment, which indicates that the primary school's facilities and equipment are relatively shortage.

Table 1 The frequency distribution of the survey subjects based on their evaluation on the sport sites and facilities and the sport equipments of their school $(n=122)$.

\begin{tabular}{ccccc}
\hline & Very good & General & Poor & Very poor \\
\hline Sport sites and facilities & $9(0.074)$ & $31(0.254)$ & $65(0.533)$ & $17(0.139)$ \\
Sport equipment & $7(0.057)$ & $36(0.295)$ & $53(0.435)$ & $26(0.213)$ \\
\hline
\end{tabular}

The PE teachers. As table 2 shows, 57 (46.7\%) of the 122 surveyed teachers are younger than 30 years, 18 (14.7\%) of them are between 30-40 years old, 9 (7.4\%) of them are between 41-50 years old, 13 (10.7\%) of them are between 51-60 years old, and 25 (20.5\%) of them are older than 60 years.

Table 2 The age distribution of the physical education teachers $(n=122)$

\begin{tabular}{ccc}
\hline Age (years) & Number & Percentage (\%) \\
\hline Under 30 & 57 & 46.7 \\
$30-40$ & 18 & 14.7 \\
$41-50$ & 9 & 7.4 \\
$51-60$ & 13 & 10.7 \\
Over 60 & 25 & 20.5 \\
\hline
\end{tabular}

As table 3 shows, only $35.2 \%$ of the PE teachers in Zhumadian primary schools have bachelor degree, but $23.8 \%$ of them do not get any higher education, $29.5 \%$ of them are of the technical secondary school education, $11.5 \%$ of them are of the specialist qualification. These results suggest that the educational background of the physical education teachers in Zhumadian primary schools is not good, and most of them are without professional PE educational background. 
Table 3 Educational background of the physical education teachers $(n=122)$

\begin{tabular}{ccc}
\hline Record of formal schooling & Number & Percentage (\%) \\
\hline Not having a degree & 29 & 23.8 \\
Technical secondary school education & 36 & 29.5 \\
Specialist qualification & 14 & 11.5 \\
Bachelor degree & 43 & 35.2 \\
\hline
\end{tabular}

It can be seen from table 4 that the PE teachers in the school examination at a disadvantage. Looking from the schools evaluation policy, PE teachers ignored the phenomenon, which is particularly serious. Many teachers reflect that "in the assessment of school PE teachers is to raise the stepmother", as some school is stated bluntly: PE teachers in the first place on teachers before the $1 / 3+1$, according to the proportion of insert after, and accounts for $69.7 \%$ of the school doesn't let PE teachers in comparison, so that even if you work well, and the achievement is also outstanding, year-end awards for, not sad indeed? Looking from the content of the assessment, the whole city area assessment of primary school PE teachers focus on review and match to teachers' teaching performance. On the surface it is to adopt democratic appraisal method and it is by all school leadership in "muddle through" PE teachers, which is irresponsible for PE teachers. Ask for itself to queue for examination and assessment of leadership or teachers went to waiting in line to other same score, other teachers may be over rating scores of odds have how old? So the primary school of PE teachers teaching evaluation system is not reasonable.

Table 4 The place of the physical education teachers in the school assessment $(n=122)$

\begin{tabular}{ccc}
\hline In the assessment of school places & Number & Percentage (\%) \\
\hline The first $1 / 3$ & 9 & 7.4 \\
The middle $1 / 3$ & 13 & 10.6 \\
The last $1 / 3$ & 15 & 12.3 \\
Absence of the assesment & 85 & 69.7 \\
\hline
\end{tabular}

Sports teachers' teaching level. Table 5 shows that a lot of primary schools' PE classes and are walking a form, $86.1 \%$ of all schools did not achieve scientific teaching method of PE teaching. Most schools are using sheep on PE teaching, the teaching approach that since primary school students in PE learning to scientific physical training methods also won't improve the physical quality to promote the effect of physical and mental health. The reasons for this situation mainly has two aspects: First of all, from the teachers' teaching level, appear this kind of circumstance is the main reason of the professional, experienced the relative lack of PE teachers. Secondly, for the requirements of $\mathrm{PE}$ from schools, appear this kind of circumstance is the main reason of the primary school of sports classroom teaching content seriously enough, attaches importance to students' safety and academic achievement [2]. So the sheep type appeared in the primary school PE class teaching, so that cannot achieve the standard of general administration of sports in our country to set up.

Table 5 primary school physical education class arrangement $(n=122)$

\begin{tabular}{ccc}
\hline content of class teaching & Number & Percentage (\%) \\
\hline Teaching lessons for a while & 37 & 30.3 \\
Free activities & 44 & 36.1 \\
entire lesson for teaching & 24 & 19.7 \\
The reasonable arrangement of the entire lesson & 17 & 13.9 \\
\hline
\end{tabular}


The table 6 shows that most of the points of sports teachers' attitudes towards sports class is not seriously enough. The main reasons why appear this kind of circumstance are: First is the primary school PE teachers in the morning exercises every day, the lesson hold, extracurricular sports training, holidays, school sport organizations and some chores, etc., make the primary school PE teachers a lot of work, and after years, sun amateur training almost without any payment, so that PE teachers felt very imbalance inside. Followed by the number of primary school classes, and limited space, the lack of equipment, all of this adds a lot of difficulties to PE teachers' classroom arrangement, coupled with professional experienced PE teachers is less, so most of the PE teachers treat attitude is not correct. Although on the surface of the present situation of our city primary school sports teaching also caused no obvious negative impact, but from the perspective of long-term development, it for our city primary school sports teaching is a potential barrier, should cause the attention of relevant departments.

Table 6 Attitude toward physical education of the physical education teachers $(n=122)$

\begin{tabular}{ccc}
\hline The attitude of the physical education class & Number & Percentage (\%) \\
\hline Seriously & 21 & 17.2 \\
general & 32 & 26.2 \\
Not seriously & 69 & 56.6 \\
\hline
\end{tabular}

\section{Summary}

There is a shortage of school sports facilities and equipment in the primary schools of Zhumadian city. The most PE teachers in the primary schools are young, and with high education level, but lack of experience. The evaluation system for the PE teachers in the primary schools is not reasonable, and the most surveyed schools do not pay enough attention to the physical education for primary students.

\section{Acknowledgements}

Corresponding author: Jiang-Hua Li. This research work was supported by National Natural Science Foundation of China under Grant No. 21365013 and Teaching Reform Project of Colleges and Universities in Jiangxi Province under Grant No. JXJG-13-2-6.

\section{REFERENCES}

[1] Liu, X.M. 2004. Primary and secondary school physical education and health teaching. people's sport publishing house 26(15):57-59.

[2] Ning, Y.M. 2008. Sunshine sports to promote the students participate in sports study. Journal of sport science and technology 23(03):12-13.

[3] Mao, Z.M. 2006. How to correctly understand and use white master study. Journal of school sports in China 9(11):34-36.

[4] Li, X.W. 2001. Physiological psychology. Journal of physical education 17(8): 23-24.

[5]Wang, F.R. 2006. Don't use the subjectivity of students instead of teachers' individuality. China Education News 34(27):12-14. 